\section{FILIPINOS AND THAIS SAYING "NO" IN ENGLISH}

\author{
Nathaya Boonkongsaen ${ }^{1}$
}

\begin{abstract}
This study investigated the use of refusal strategies conducted in English between Filipinos and Thais. The purpose of the study was to examine if the frequency of refusal strategies varied according to the situations and social status of the interlocutors. Data were collected through a discourse completion task (DCT). Findings indicated that both groups preferred to use indirect strategies to the direct ones. In general, Filipinos were more direct than Thais when dealing with refusals. Thais were less direct than Filipinos when declining the interlocutor of higher status. As language and culture are intimately related, English refusal strategies used by Filipinos and Thais reflected tendencies in their social norms.
\end{abstract}

Keywords: Refusal Strategies, Refusal Speech Acts

\section{Introduction}

The concept of speech acts was first introduced by Austin, a British philosopher (1962), and was further developed by J. R. Searle, an American philosopher (1969). According to Searle (1969), the speech act is recognized as a basic linguistic unit of communication and meaning. Examples of speech acts include apologizing, giving and responding to compliments, complaining, making

\footnotetext{
${ }^{1}$ Lecturer, Faculty of Education, Vongchavalitkul University
}

requests, making refusals, etc. Refusal is a speech act that we often perform in our daily lives and that can occur in any language. It is not a speech act initiated by the speaker but a response by the speaker to the interlocutor who may make a request, invitation, offer, suggestion, etc.

Refusal is used when a speaker "denies [sic] to engage in an action proposed by the interlocutor" (Chen, Ye \& Zhang, 1995: 121). According to Beebe and Takahashi, (1989) refusals are considered "face-threatening acts" (FTAs). In other words, one's saying no is like committing an offense against his/her interlocutors. One of the central concepts of linguistic pragmatics is politeness, which was suggested by Lakoff (1972), Brown and Levinson (1978) and Leech (1980, 1983). The well known explicit mode of politeness proposed by Brown and Levinson (1978) (reissued 1987) suggests that an abstract underlying social principle guides and constrains the speaker's choices of language in every discourse. Three sociolinguistic factors that determine the level of politeness are 1) the social distance between speaker and hearer (D), 2) the relative power relationship between speaker and hearer (P), and 3) the ranking of the particular imposing (R). Since refusals can be face-threatening, the speaker may elaborate some strategies that minimize the threats. Refusals can be conducted by means of both direct and indirect strategies, the use of which depends on sociolinguistic factors.

Several previous research works have been carried out to compare refusals given by native (NSs) and non-native speakers (NNSs) of English, such as American English speakers and Iranian learners of English (Sadeghi and Savojbolaghchilar, 2011), American English and Chinese 
(Honglin, 2007), American English speakers and Thai learners (Wannaruk, 2004), American English speakers and Egyptian Arabic speakers (Nelson, Carson, Batal and Bakary, 2002a) etc. Through the review of related literature, it appears that contrastive studies of English refusal strategies employed by NNSs of English are scarce. The NNSs of English with different cultures may elaborate English refusal strategies within their cultural norms. The present study examines English refusal strategies employed by Filipinos and Thais. The initiating acts are requests, offers, invitations and suggestions. The rationale for choosing these two groups, who are of particular interest to the researcher in pragmatics, is that among Asian countries, Philippine society is considered a unique blend of eastern and western cultures resulting from trade and conquest in earlier times (Quisumbing, 2004), while Thailand has never been colonized by any country. This may imply that Thailand still maintains its traditional culture and norms compared with the Philippines. One of the core values of Filipino personhood is equality. "Kapwa" implies a moral obligation to treat others as equals. That is, "people are just people in spite of their age, clothes, diplomas, color or affiliations" (Guia, 2005: 2). On the other hand, Thais place great value on deferential behavior and submissiveness (Knutson, n.d). In addition, "Thais are taught to obey and respect people with higher status by birth, education, or knowledge and age" (Nakata and Dhiravegin, 1989: 169). These situations may contribute to the possibility of variation in the strategy used when dealing with refusals by people from the two respective countries. Furthermore, the two groups are non-native speakers (NNSs) of English who are teachers of English living in Nakhon Ratchasima, Thailand.

\section{Literature Review}

\section{The Speech Act of Refusal}

A number of researchers have provided definitions of refusals based on their different perspectives. According to Gass and Houck (1999: 2), refusals are considered "one of a relatively small number of speech acts which can be characterized as a response to another's act (e. g. to a request, invitation, offer, suggestion), rather than as an act initiated by the speaker." In the view of Daly, Holmes, Newton and Stubbe (2004: 948), refusals are "highly face threatening speech acts because they involve the rejection of a request which the communicator felt was legitimate to make". According to Chen, Ye and Zhang (1995: 121), refusal is a speech act by which a speaker "denies to engage in an action proposed by the interlocutor [sic]." While definitions may vary slightly, they generally agree that refusals are not initiated by speakers but are a response to interlocutors. Refusals can be facethreatening as the speaker declines to engage in actions such as requests, invitations, offers and suggestions proposed by the interlocutor.

\section{Politeness Theory}

To communicate successfully, it is imperative that speakers cooperate. In this respect, Grice (1975) proposes the Cooperative Principle that operates in terms of four maxims for achieving communication. The four maxims are quantity, quality, relevance and manner. According to Grice, speakers need to be informative, accurate, relevant and clear in order to communicate efficiently. In reality, however, people do not always comply with these maxims. Sometimes 
people argue, lie, scold etc. Grice's theory was a foundation for further studies. Lakoff's (1973) politeness rule, Leech's (1983) politeness principle and maxims, and Brown and Levinson's (1978, 1987) politeness strategies complemented Grice's framework. Lakoff defines politeness as "a system of interpersonal relations designed to facilitate interaction by minimizing the potential for conflict and confrontation inherent in all human interchange" (cited in Eelen, 2001: 2). Leech (1983) views politeness as 'interpersonal rhetoric'. Brown and Levinson (1987) see politeness as conflict avoidance and introduce the concept of 'face', which is considered as the "public self-image that every member wants to claim for himself" (Brown and Levinson, 1987: 402). There are two kinds of face, positive and negative. "Positive face refers to the desire for appreciation and approval while negative face refers to the desire to be unimpeded in one's actions." Brown and Levinson further indicate that some speech acts might threaten either the hearer's or the speaker's face-wants. Therefore, politeness serves to minimize such face-threats. The notion of "politeness" is socially determined as it is related to social differentiations and to making appropriate choices which are situationally dependent and may differ for all interlocutors (Coulmas, 2005). To put it another way, what is considered polite or impolite may vary according to different contexts and cultures as it can be interpreted differently by people who believe in different sets of values.

\section{Previous Contrastive Studies of Refusal Strategies}

Contrastive studies of refusal strategies have received a great deal of attention particularly in refusal speech acts across languages. In spite of the fact that discourse completion tasks (DCTs) are controversial methods and often challenged by many researchers due to their lack of authenticity (Lingli and Wannaruk, 2010), they have been used as a means of data collection by many previous researchers. For example, Beebe, Takahashi and Uliss Weltz (1990) compared the refusals employed by Japanese and native speakers of English. Findings revealed a relationship between status and the directness of refusals. That is, Japanese opted to use more direct strategies when refusing interlocutors of lower status and more indirect strategies when refusing interlocutors of higher status. Americans tended to employ indirect strategies in all situations.

Nelson, Carson, Batal and Bakery (2002b) investigated the similarities and differences of refusal strategies employed by Egyptian Arabic speakers and speakers of American English. Data were analyzed to compare the average frequencies of direct and indirect strategies across the two groups. Findings indicated that both groups used similar strategies at similar frequencies in making refusals. Wannaruk (2004) examined the similarities and differences between Thais and Americans in their refusal strategy use. The findings showed that the two groups employed similar strategies with different frequency. Types of eliciting acts and social status affected the use of refusal strategies. Honglin (2007) conducted a comparative study of speech acts of refusal among native Chinese and American English speakers. The findings revealed that refusals vary in directness with situations and cultures. The situational variability of directness in both languages follows a similar trend and Americans are more direct than Chinese. In another study, 
Sadeghi and Savojbolaghchilar (2011) investigated the refusal strategies employed by four groups of native and non-native speakers of English namely, American English speakers, Persian/Azeri speakers, advanced Iranian learners of English, and Iranians living in the USA. The findings showed that Iranian advanced learners in Iran used different strategies to refuse requests, invitations, offers and suggestions from Iranians living abroad, who acted more similar to American native speakers.

While previous research has compared refusals given by native (NSs) and nonnative speakers (NNSs) of English, English refusal strategies employed among NNSs of English have been underresearched in the literature. More research is needed to fill the gaps. To decline an L2 speaker without causing offense or misunderstanding is quite challenging for another non-native speaker. Their selection of refusal strategy might indicate the traditional values of their culture.

\section{Objective of the Study}

This study aims at investigating English refusal strategies employed by Filipinos and Thais. The purpose of this study is threefold:

1. To investigate the frequency of direct and indirect strategies employed by Filipinos and Thais;

2. To examine whether or not the frequency of refusal strategies employed by the two groups is different in four situations; and

3. To examine whether or not social status affects strategy use.

\section{Research hypotheses}

1. There is a significant difference in the frequency of direct and indirect strategies employed between Filipinos and Thais.

2. There is a significant difference in the frequency of refusal strategies employed between the two groups with reference to the four situations.

3. There is a significant difference in the frequency of refusal strategies employed between the two groups with reference to social status.

\section{Methodology}

\section{Data collection}

Data were collected by means of a discourse completion task (DCT). DCT has been recognized as an effective means of collecting data on communicative acts as it is consistent with naturally occurring data, especially in the main patterns and formulas (Golato, 2003). Furthermore, DCT is beneficial because the researcher can provide a specific speech act as well as control the social status and distance between interlocutors (Wannaruk, 2005). Twelve situations in DCT were developed on the basis of interviews conducted with a view to possible situations for refusals. They were categorized into four types of eliciting act: three invitations, three suggestions, three offers and three requests. In each type of eliciting act, the participants were required to make an English refusal to interlocutors of higher, equal and lower status. The rationale behind choosing these four stimulus types was that the refusal classification used to analyze refusal strategies in the present study was developed by Beebe et al. (1990) who developed this model based on these 
four stimulus types in which the refuser status was classified as lower, equal or higher. The four stimulus types (invitations, suggestions, offers and requests) have been used widely as model situations by many previous researchers in conducting comparative studies of refusals (e.g. Sadeghi and Savojbolaghchilar, 2011; Honglin, 2007 and Nelson, Carson, Batal and Bakery 2002a).

\section{Participants}

To accomplish the purpose, two groups of participants took part in this research: 30 Filipino (13 males and 17 females) and 30 Thai teachers of English (8 males and 22 females) living in Nakhon Ratchasima province, Thailand. The native languages of the Filipino teachers were Tagalog, Kankanaey and Cebuano. The native language of the Thai teachers was Thai. The age of the participants was within the range of 23-45. Since the present study aimed to reveal the English refusal strategies used by the two groups, the participants were, therefore, required to provide their refusals in English.

\section{Data Analysis}

The participants' responses to each eliciting act were analyzed based on the refusal classifications developed by Beebe et al. (1990; see appendix) which were employed in the previous studies. The frequency of semantic formulae used by the participants was counted. For example, if a respondent refused the principal's invitation, saying, 'Thank you for inviting me, sir. I'd love to come but I've already promised my aunt to visit her this Friday', this response was coded as consisting of three refusal strategies as presented in Table 1.
Table 1: Examples of Semantic Formulae

\begin{tabular}{lll}
\hline Gratitude & $\begin{array}{l}\text { Positive } \\
\text { feeling }\end{array}$ & Explanation \\
\hline $\begin{array}{l}\text { "Thank you } \\
\text { for inviting } \\
\text { me sir." }\end{array}$ & to come"d love & "but I've \\
& & $\begin{array}{l}\text { already } \\
\text { promised } \\
\text { my aunt to } \\
\end{array}$ \\
& & visit her \\
& & this \\
& & Friday". \\
\hline
\end{tabular}

The procedures for analysis can be described as follows: First, the refusal strategies were analyzed based on the classifications developed by Beebe et al. (1990). Second, the total number of semantic formulae employed by each group was counted in overall use, in each eliciting act and in response to interlocutors of higher, equal and lower status. Third, the comparison of frequency of semantic formulae employed by the two groups was made by means of a chi-square test.

\section{Reliability of coding}

The data obtained through DCT were coded by two raters who were English native speakers. To validate the reliability of coding, inter-rater reliability was used as a means to test consistency in categorizing the data. The results revealed a high level of consistency in categorizing the data (94\%). However, there were a few discrepancies on how to categorize certain refusal responses. To deal with the discrepancies, any differences between their judgment on coding were discussed. The ambiguities in coding came to light through these discussions. 


\section{Findings}

Findings are presented in three parts in accordance with the purposes of the study. The frequency of direct and indirect refusal strategies used by Filipinos and Thais is compared. In addition, the three most frequently used semantic formulae are also presented. Examples of responses made by the participants are shown without any grammatical corrections.

\section{Overall Picture of Refusal Strategies Employed by Filipinos and Thais}

Table 2: Frequency of Refusal Strategies employed by Filipinos and Thais

\begin{tabular}{|c|c|c|c|}
\hline & Direct & Indirect & $\begin{array}{l}\text { Top three } \\
\text { semantic } \\
\text { formulae }\end{array}$ \\
\hline$\overline{\mathrm{FL}}$ & 94 & 618 & $\begin{array}{l}\text { 1.Explanation } \\
(65 \%) \\
2 . \text { Regret } \\
(31.4 \%) \\
\text { 3.Gratitude } \\
(24.7 \%)\end{array}$ \\
\hline $\mathrm{TH}$ & 65 & 673 & $\begin{array}{l}\text { 1. Explanation } \\
(83 \%) \\
2 . \text { Regret } \\
(34.2 \%) \\
3 . \text { Gratitude } \\
(30 \%)\end{array}$ \\
\hline
\end{tabular}

Sig. $\mathrm{P}<.05 \quad$ N.S.
Note: N.S. $=$ not significant

Table 2 reveals that Filipinos and Thais tended to use indirect strategies much more frequently than direct ones when dealing with refusals. Filipinos employed direct strategies more frequently than their Thai counterparts, and this difference was found to be statistically significant $(p<0.05)$. This seems to indicate that overall, the two groups are similar in that they seldom say 'No' or 'I can't' or 'I won't' to the interlocutors. This could be because that the two groups try to soften threats or damage that might occur to the hearer's face when he/she asks for a favor. Therefore, the two groups of speakers came up with elaborate indirect strategies. When taking a closer look at the frequency of direct strategy use, Filipinos tended to be more direct than their Thai counterparts as pointed out by a significant difference in the frequency of direct strategies employed between the two groups. This indicates that Thais say 'No' or 'I can't' or 'I won't' to the interlocutors less frequently than Filipinos. Indirect strategies seem to be the favored choices among both groups as Filipinos and Thai employed indirect strategies much more frequently than direct strategies. Filipinos and Thais did not differ in the frequency of indirect strategies employed as the result shows no existing statistical significance. With respect to the top three semantic formulae, the apparent trend demonstrates that both groups followed the same pattern. Explanation was the most frequently used strategy followed by Regret and Gratitude.

\section{Refusal Strategies Employed by Filipinos in Four Eliciting Acts}

The frequency of refusal strategies shown in the preceding section gives us an overall picture of Filipinos' and Thais' use of strategies in dealing with refusals. This section will describe the two groups' strategies used in a more detailed manner, i.e. in four eliciting acts. It will examine whether or not the two groups are similar in terms of choice and frequency of refusal strategy used in invitations, suggestions, offers and requests. 


\section{Refusal Strategies to Invitations}

Table 3: Frequency of Refusal Strategies to Invitations

\begin{tabular}{|c|c|c|c|}
\hline & Direct & Indirect & $\begin{array}{l}\text { Top three } \\
\text { semantic } \\
\text { formulae }\end{array}$ \\
\hline FL & 27 & 163 & $\begin{array}{l}\text { 1. Explanation } \\
(83.3 \%) \\
\text { 2.Regret } \\
(44.4 \%) \\
\text { 3.Negative } \\
\text { willingness } \\
(28.9 \%)\end{array}$ \\
\hline TH & 21 & 171 & $\begin{array}{l}\text { 1. Explanation } \\
(92 \%) \\
2 . \text { Positive } \\
\text { feeling } \\
(44.4 \%) \\
\text { 3.Gratitude } \\
(25.6 \%)\end{array}$ \\
\hline
\end{tabular}

Table 3 indicates that in invitations, Filipinos and Thais employed indirect strategies more frequently than direct ones. Filipinos were likely to employ direct strategies more frequently than Thais while Thais made more use of indirect strategies than Filipinos. However, these differences were not statistically significant. With regard to the top three semantic formulae, 'Explanation' was employed most by the two groups. The second and the third most common strategies employed by the two groups were different. Examples of refusal to invitations are presented below:

Refusing a principal's invitation to a party

Principal: We're going to have a school year party this Friday. Will you be able to join?
FL(R3): 'I'm sorry . I already have my appointment on that day' [sic]. (Regret/Explanation)

TH(R10): 'I'm very appreciated to come there but I'm afraid that I will not be able to come because I need to visit my mom[sic]. She's admitted in the hospital' [sic]. (Positive feeling/Negative ability /Explanation)

Principal: 'Oh! that's too bad. I thought you could come'.

\section{Refusal Strategies to Suggestions}

Table 4: Frequency of Refusal Strategies to Suggestions

\begin{tabular}{llll}
\hline & Direct & Indirect & $\begin{array}{l}\text { Top three } \\
\text { semantic } \\
\text { formulae }\end{array}$ \\
\hline FL & 23 & 139 & $\begin{array}{l}1 . \text { Explanation } \\
(62.2 \%)\end{array}$ \\
& & & $\begin{array}{l}2 . \text { Regret } \\
(27.8 \%)\end{array}$ \\
& & & 3. Negative \\
& & & \\
& & & $(20 \%)$ \\
& & & 1. Explanation \\
& & & $(86.7)$ \\
TH & 17 & \multirow{2}{*}{159} & 2. Gratitude \\
& & & $(32.2 \%)$ \\
& & & 3. Regret \\
& & & \\
& & & \\
\hline Sig & N.S. & N.S. & \\
\hline
\end{tabular}

Table 4 demonstrates that in dealing with suggestions, the two groups preferred indirect strategies to direct ones. There was no statistical difference in frequency of employing direct and indirect strategies between the two groups. The first common strategy used by both groups was 'Explanation'. The second and the third 
most frequently used strategies were different for the two groups. Examples of refusals to suggestions are presented below:

Refusing a friend's suggestion to read a newly released book

Your friend: 'This is a great book! I recommend that you read it.'

Filipino (R9): 'No, thanks, friend. I've not yet finished with the book I'm reading.' (No/Gratitude/Explanation)

Thai (R 16): 'Thank you for recommend, but I don't have time.' (Gratitude/Explanation)

Your friend: Why not?

Refusal Strategies to Offers

Table 5: Frequency of Refusal Strategies to Offers

\begin{tabular}{|c|c|c|c|}
\hline & Direct & Indirect & $\begin{array}{l}\text { Top three } \\
\text { semantic } \\
\text { formulae }\end{array}$ \\
\hline $\mathrm{FL}$ & 18 & 170 & $\begin{array}{l}\text { 1. Gratitude } \\
61.1 \%) \\
\text { 2.Let the } \\
\text { interlocutor } \\
\text { off the hook } \\
(52.2 \%) \\
\text { 3.Explanation } \\
(41.1 \%)\end{array}$ \\
\hline $\mathrm{TH}$ & 4 & 178 & $\begin{array}{l}\text { 1. Gratitude } \\
(76.7 \%) \\
\text { 2.Explanation } \\
(63.3 \%) \\
\text { 3.Let the } \\
\text { interlocutor } \\
\text { off the hook } \\
(25.5 \%)\end{array}$ \\
\hline Sig & $\mathrm{P}<.005$ & \multicolumn{2}{|l|}{ N.S. } \\
\hline $\begin{array}{l}\text { Table } \\
\text { empl } \\
\text { frequ } \\
\text { offers }\end{array}$ & $\begin{array}{l}5 \text { shows } \\
\text { yed in } \\
\text { ntly that } \\
\text { Filipino }\end{array}$ & $\begin{array}{l}\text { hat } \mathrm{Fi} \\
\text { ect } \\
\text { direct } \\
\text { mploy }\end{array}$ & $\begin{array}{l}\text { los and Thai } \\
\text { tegies mor } \\
\text { is in refusin } \\
\text { irect strategie }\end{array}$ \\
\hline
\end{tabular}

more frequently than Thais. The difference was statistically significant $(\mathrm{p}<.005)$. However, the frequency of employing indirect strategies between Filipinos and Thais was more or less the same.

'Gratitude' was the most first commonly used strategy among them. 'Let the interlocutor off the hook' was the second most common strategy for Filipinos while 'Explanation' was for Thais. The third most common strategies for Filipinos and Thais were 'Explanation' and 'Let the interlocutor off the hook', respectively. Examples of refusals to offers are presented below:

Refusing a friend's offer to help you carry books

Your friend: 'You're carrying lots of books. Let me help you!'

FL (R23): 'It's okay. I can carry them on my own'. (Let the interlocutor off the hook (Explanation)

TH (R26): 'Thanks, but they're not too heavy.'(Gratitude /Explanation)

Your friend: 'Are you sure'?

\section{Refusal Strategies to Requests}

Table 6: Frequency of Refusal Strategies to Requests

\begin{tabular}{|c|c|c|c|}
\hline & Direct & Indirect & $\begin{array}{l}\text { Top three } \\
\text { semantic } \\
\text { formulae }\end{array}$ \\
\hline$\overline{\mathrm{FL}}$ & 26 & 146 & $\begin{array}{l}\text { 1. Explanation } \\
(76.7 \%) \\
\text { 2.Regret } \\
\text { (50\%) } \\
\text { 3.Negative } \\
\text { willingness }\end{array}$ \\
\hline
\end{tabular}




\begin{tabular}{llll}
\hline & & & $(17.8 \%)$ \\
TH & 23 & 165 & \\
& & & $($. Explanation \\
& $(90 \%)$ \\
& & & 2. Regret \\
& & $(60 \%)$ \\
& & & 3. No $(13.3 \%)$ \\
& & & 4. Positive \\
& & & feeling \\
& & & $(13.3 \%)$ \\
\hline Sig & N.S. & N.S. & \\
\hline
\end{tabular}

As shown in Table 6, Filipinos and Thais employed indirect strategies more frequently than direct ones in refusing to requests. The frequency of employing direct and indirect strategies between the two groups was not statistically different. Filipinos and Thais followed the same pattern for the first and second most commonly used strategies. 'Negative willingness' was the third most commonly used strategy for Filipinos while 'No' and 'Positive feeling' were for Thais. Examples of refusals to requests are presented below:

Refusing a neighbor's request to mail a package at the post office

Your neighbor: 'The post office is on the way to your office. Can you help me with this package? I want to mail it to my sister'.

FL (R16): 'Oh, I really would love to but you know, I have to be in a meeting in 15 minutes. I'm afraid I can't make it. (Positive feeling/Explanation/ Negative willingness)

TH (R17): 'Sorry, I'm in a hurry this morning. Tomorrow will be fine'. (Regret /Explanation/ Promise of future acceptance)

Your friend: 'Alright.' 'No problem!'
Refusal Strategies to Interlocutor of Different Status

As every society concerns a normative notion of politeness (Coulmas, 2005) to mitigate FTA, speakers may elaborate some strategies that avoid committing face-threatening acts and are able to maintain good relations between them. One of the sociolinguistic factors that has received wide attention in relation to the study of refusal strategy used is interlocutor status as it may affect the choice and frequency of the speakers in dealing with refusals. The findings suggest that interlocutor status affects Filipinos and Thais in terms of their strategy choice and frequency, shown below.

\section{Refusal Strategies to Interlocutor of Higher Status}

Table 7: Frequency of Refusal Strategies to Interlocutor of higher status

\begin{tabular}{|c|c|c|c|}
\hline & Direct & Indirect & $\begin{array}{l}\text { Top three } \\
\text { semantic } \\
\text { formulae }\end{array}$ \\
\hline$\overline{\mathrm{FL}}$ & 27 & 224 & $\begin{array}{l}\text { 1. Explanation } \\
(74.2 \%) \\
2 . \text { Regret } \\
(41.7 \%) \\
\text { 3.Gratitude } \\
(19.2 \%)\end{array}$ \\
\hline $\mathrm{TH}$ & 14 & 251 & $\begin{array}{l}\text { 1. Explanation } \\
(82.5 \%) \\
2 . \text { Regret } \\
(42.5 \%) \\
\text { 3.Positive } \\
\text { feeling }(33.3 \%)\end{array}$ \\
\hline Sig & $\mathrm{P}<.05$ & \multicolumn{2}{|l|}{ N.S. } \\
\hline \multicolumn{4}{|c|}{$\begin{array}{l}\text { Table } 7 \text { demonstrates that indirect } \\
\text { strategies are employed by Filipinos and } \\
\text { Thais more frequently than direct ones. } \\
\text { Filipinos employed direct strategies more } \\
\text { frequently than their Thai counterparts. }\end{array}$} \\
\hline
\end{tabular}


The difference was found to be statistically significant $(p<0.05)$. However, the frequency of employing indirect strategies between the two groups was not statistically different. Filipinos and Thais followed the same pattern for the first and second most commonly used strategies. 'Gratitude' was the third commonly used strategy for Filipinos while 'Positive feeling' was used by Thais.

\section{Refusal Strategies to Interlocutor of Equal Status}

Table 8: Frequency of Refusal Strategies to Interlocutor of Equal Status

\begin{tabular}{llll}
\hline & Direct & Indirect & $\begin{array}{l}\text { Top three } \\
\text { semantic } \\
\text { formulae }\end{array}$ \\
\hline FL & 23 & 214 & $\begin{array}{l}1 . \text { Explanation } \\
(68.3 \%)\end{array}$ \\
& & & $\begin{array}{l}2 . \text { Gratitude } \\
(31.7 \%)\end{array}$ \\
& & & 3. Regret \\
& & & $\begin{array}{l}29.2 \%) \\
\end{array}$ \\
& & & 1. Explanation \\
TH & 16 & 227 & \\
& & & 2. Regret \\
& & & $(39.2 \%)$ \\
& & & 3. Gratitude \\
& & & $(35 \%)$ \\
\hline Sig & N.S. & N.S. & \\
\hline
\end{tabular}

Table 8 indicates that Filipinos and Thais employed indirect strategies more frequently than direct ones. The statistics showed no significant difference in employing direct and indirect strategies between them. 'Explanation' was most commonly used for the two groups. 'Gratitude' and 'Regret' were second most commonly used for Filipinos and Thais, respectively. 'Regret' was the third most commonly used strategy for Filipinos while 'Gratitude' was for Thais.

\section{Refusal Strategies to Interlocutor of Lower Status}

Table 9: Frequency of Refusal Strategies to Interlocutor of Lower Status

\begin{tabular}{|c|c|c|c|}
\hline & Direct & Indirect & $\begin{array}{l}\text { Top three } \\
\text { semantic } \\
\text { formulae }\end{array}$ \\
\hline FL & 44 & 180 & $\begin{array}{l}\text { 1. Explanation } \\
(55 \%) \\
\text { 2.Regret / } \\
\text { Gratitude } \\
(23.3 \%) \\
\text { 3.Negative } \\
\text { willingness } \\
(21.7 \%)\end{array}$ \\
\hline $\mathrm{TH}$ & 35 & 195 & $\begin{array}{l}\text { 1. Explanation } \\
(79.2 \%) \\
2 . \text { Gratitude } \\
(34.2 \%) \\
\text { 3.Regret } \\
(20.8 \%)\end{array}$ \\
\hline Sig & N.S. & N.S. & \\
\hline
\end{tabular}

Table 9 demonstrates that Filipinos and Thais were alike in terms of employing indirect strategies more frequently than direct ones. The frequency of employing indirect strategies and direct strategies between these two groups was not statistically different. Regarding the top three semantic formulae, 'Explanation' was the most frequent strategy for the two groups. 'Regret' and 'Gratitude' were the second most commonly used strategies for Filipinos while 'Gratitude' was for Thais. 'Negative willingness' and 'Regret' were the third most commonly used strategies for Filipinos and Thais, respectively. 


\section{Discussion and Conclusion}

\section{Refusal Strategies in General}

On the whole, the findings partially support the hypothesis that there is a significant difference in the frequency of direct and indirect strategies between Filipinos and Thais. The two groups are not different in the frequency of employing indirect strategies but in the frequency of employing direct strategies. Filipinos and Thais preferred to use indirect refusal strategies to direct ones. This implies that they avoided expressing the feeling of unwillingness to do or accept something directly. They used indirect strategies in order to avoid annoyance. It could not be concluded that Filipinos and Thais wanted to be polite to the interlocutors as they employed indirect strategies more frequently than direct ones since not all the indirect strategies were considered polite. For example, in refusing a student's request to work in groups of ten, one of the participants said; "The way you asked me is not wise. It is better to have a group of five to facilitate effective learning." It can be seen that the speaker's answer sounds sarcastic and critical.

When refusing, Filipinos employed direct strategies more frequently than Thais. This might indicate that Filipinos were more straightforward in saying no or expressing their negative willingness while Thais tried to soften their refusals with indirect strategies. "Social harmony is valued by Thais and overt expression of conflict is discouraged." For Thais, "one's feeling should be kept to oneself" (Mulder, 1992: 71). In this study, direct refusal strategies were used less frequently by Thais. Even though they were asked to use L2 to deal with refusals, the L2 they used mirrored Thai social values. It can be claimed that the speech act of refusal carries social implications for both groups in relation to their social interaction, politeness and face.

There is no right or wrong strategy to deal with refusals. It is important that the speakers understand each other's culture. To consider the refusal patterns of the interlocutor's culture, Filipinos and Thais can avoid engaging in face-threatening acts. It was also noted that both groups favored Explanation more than the other strategies. The findings of the present study were partially consistent with Wannaruk's (2005) which revealed that Explanation was most frequently used by both native (NSs) and non-native speakers (NNSs) of English. Based on the content analysis of refusals of the two groups, Filipinos and Thais provided clear explanations when declining their interlocutors. For example, Filipino (R13) 'I'm willing to help you, but I'm in a hurry, I have something to catch up.' Thai (R 26) 'Oh, I'm sorry to say that I have to pick up my friend. I'm not going that way'. It is possible that because all the participants were teachers of English, their English proficiency levels were high enough for them to be able to provide clear and acceptable reasons when declining the interlocutors.

Both Thais and Filipinos frequently used Regret followed by Explanation, such as "I'm sorry. I've got to start working early today". The frequent use of Regret followed by Explanation might be related to classroom instructions. This pattern seemed to be normally introduced in English language classrooms. Gratitude was the third most commonly used strategy for both groups. The findings were consistent with those of Nelson, Batal and Bakery (2002a), who discovered 
that Gratitude was used less by NNSs compared with NSs of English.

\section{Refusal Strategies in Four Eliciting Acts}

The use of indirect strategies between Filipinos and Thais in four eliciting acts was not significantly different, while the use of direct strategies in one out of four showed significant difference. It appeared that in declining offers, Thais used direct strategies less frequently than Filipinos. The findings of the study partially support the hypothesis that there is a significant difference in the frequency of refusal strategies employed by the two groups with reference to the four eliciting acts. As mentioned earlier, differences in Filipino and Thai history and cultural values might influence variations in refusal strategy used between the two groups. However, these differences might not be so significant with regard to preferences for strategy choices in response to some acts (e.g. invitations, suggestions, requests) as the data show that no significant differences exist in these three eliciting acts. However, some variations in their strategy choices can be detected for "offers". For the Thais, "offers" were more threatening than for the Filipinos. Thais tried to preserve the face of interlocutors and maintain good relations by being less direct in this eliciting act.

It is important to note that there was a discrepancy that affected Filipinos' and Thais' refusal strategy choice to some extent. People from two different cultural backgrounds and with different values responded negatively to offers differently even when using the same linguistic code, which is English. The findings obtained provided insight into their perception of the four different eliciting acts and their production of refusals. Concerning the top three semantic formulae employed by the two groups, surprisingly, Filipinos followed the same pattern in which the semantic formulae were frequently used in three eliciting acts of invitations, suggestions and requests. However, Thais did not follow the same pattern in the four eliciting acts.

\section{Refusal Strategies and Social Status}

With regard to the use of refusal strategies to interlocutors of higher, equal and lower status, the findings from this study reveal more similarities than differences among Filipinos and Thais. Both groups preferred to use indirect strategies. Compared with Filipinos, Thais employed direct strategies less when declining interlocutors of higher status. The hypothesis of this study is that there is a significant difference in the frequency of refusal strategies employed by the two groups with reference to social status. The findings partially support this hypothesis. As emerged from the data, Thais were reluctant to be direct when declining a person of higher status. Possibly Thais wanted to save the interlocutor's face so they softened their refusal with indirect strategies. It was apparent that Thai culture was reflected in English used by Thais. According to Intachakra (2004: 57), Thailand is a hierarchy-sensitive society as can be seen when someone offers an apology when she/ he happens to walk past a person holding a higher social status who is seated. In Thai culture, this manner is considered to be polite. However, this situation does not call for an apology in other societies. The findings of this study differ from those of Wannaruk (2008) who studied pragmatic transfer in Thai EFL refusals, revealing that awareness of a person in a higher status motivates 
pragmatic transfer. In Wannaruk's study (2008), direct strategies were frequently used when a tutor, a person in a higher status, was faced with his or her students' suggestions. Wannaruk explained that in most interpersonal communication in Thai culture, a person of higher status tends to be 'assertive' and 'expressive'. Therefore, it is appropriate to say "No" or "I can't" directly to an interlocutor of lower status. What has been found in the present study and in Wannaruk's (2008) affirms that Thailand is a social-ranking sensitive society. In the matter of awareness of a person in a higher status, transfer from Thai culture to L2 was found in Wannaruk's study. Awareness with regard to transfer from Thai culture to L2 of a person in a lower status has also been detected in the present study.

The findings suggest that Filipinos value equality while Thais value social hierarchy. The value of equality permeates the Filipinos' mind. When they are dealing with refusals to interlocutors of higher status in L2, they are more direct than the Thais. Filipinos may use the same refusal strategy to decline an interlocutor of a higher, equal or lower status. No mitigation strategies are needed to reaffirm the social order of the interlocutors. Thais are more sensitive to social rank than Filipinos. To decline interlocutors of higher status, Thais are considerate in order to avoid embarrassing or imposing upon them. Thais are concerned with the selection of refusal strategies when talking to interlocutors of higher status as they could be considered disrespectful and offensive if they are very direct.

\section{Pedagogical Implications}

The present study contributes to crosscultural communication by revealing cross-cultural and linguistic differences between Filipino and Thai teachers of English. This study has implications for language teachers. That is, to avoid conflicts and situations of communicative breakdown which could happen in any communicative act, language teachers teaching English in another country should be aware of the norms and values of the students' in those countries. It is undeniable that to teach a foreign language is to teach a foreign culture. However, it is imperative to be aware that students who learn a foreign language do not share the values of the L2 or the teacher's native culture. Pedagogically, this study also has implications for the development of students' L2 pragmatic competence. With limited exposure to L2 norms, students should be assigned to compare and contrast norms and cultural differences in L1 and L2 in a particular communicative act being studied. It could help develop the students' ability to use the target language in a socially and culturally appropriate manner. Regarding foreign language teaching materials, apart from focusing on grammar, the lesson should leave room for L2 pragmatic aspects. That is, the lesson should be designed to incorporate tasks that focus on L2 pragmatic knowledge. Audio-visual materials should reveal various situations with different social constraints in the target language. Provided with the necessary information and language choices, students will be able to become competent users of the target language.

\section{Limitations and Suggestions for Further Research}

It might not be possible to generalize the findings of the study to all Filipino and Thai people. Nonetheless, the evidence obtained in this study may provide insights 
into refusals in English made by Filipinos and Thais whose cultural norms and values are not similar. Carrying out research by employing oral role-play might yield further insight. Gender, which is a social variable, should be taken into consideration as a factor that might contribute to the variation of refusal strategy use. In addition, when conducting a further study on this subject, some changes in eliciting acts could be needed in order to obtain a more comprehensive picture of refusal strategy use.

\section{References}

Austin, J. L. 1962. How to Do Things with Words. New York: Oxford UP.

Beebe, L. M, and T. Takahashi. 1989. Sociolinguistic variation in facethreatening speech acts:

chastisement and disagreement. In the Dynamic Interlanguage: Empirical Studies in Second Language variation, edited by M. Eisenstein, pp.199-218.

New York: Plenum.

Beebe, L. M., T. Takahashi and R. UlissWeltz. 1990. Pragmatic transfer in ESL refusals. In Developing Communicative Competence in a Second language, edited by R. Scarcella, E. Anderson. and S. Krashen, pp. 55-73. New York: Newbury House.

Brown, P. and S. C. Levinson. 1978. Universals in language usage: politeness phenomena. In Questions and Politeness: Strategies in Social Interaction, edited by E. N. Goody, pp. 56-289. Cambridge, UK: Cambridge UP.
---. 1987. Politeness: Some Universals in Language Usage. Cambridge: Cambridge UP.

Chen, X., L. Ye, and Y. Zhang. 1995. Refusing in Chinese. In Pragmatics of Chinese as a Native and Target Language, edited by G. Kasper, pp. 119-163. Honolulu: University of Hawai'i Press.

Coulmas, F. 2005. Sociolinguistics: The Study of Speaker's Choice. Cambridge: Cambridge UP.

Daly, N., J. Holmes, J. Newton, and M., Stubbe. 2004. Expletives as solidarity signals in FTAs on the factory floor. Journal of Pragmatics 36: 945-964.

Eelen, G. 2001. A Critique of Politeness Theories. Manchester: St. Jerome Publishing.

Gass, S. M. and N. Houck. 1999. Interlanguage Refusals: a CrossCultural Study of Japanese-English. New York: Mout De Gruter.

Golato, A. 2003. Studying compliment responses: a comparison of DCTs and recording of naturally occurring talk. Applied Linguistics 1: 90-121.

Grice, H. Paul. 1975. Logic and conversation. In Syntax and Semantics, vol. 3: Speech Acts edited by P. Cole and J. Morgan, pp. 41-58. New York: Academic Press.

Guia, Katrin De. 2005. Indigenous Filipino values: a foundation for a culture of non-violence. Paper prepared for the forum: Toward A Culture of Non-Violence. 
April 13, 2013.

$<$ http://denmark.ph/filer/IndigenousFilipino-Values.pdf.>

Honglin, L. 2007. A comparative study of refusal speech acts in Chinese and American English. Canadian Social Science 3, 4: 64-67.

Intachakra, S. 2004. Contrastive pragmatics and language learning: Apologies and Thanks in English and Thai. Regional Language Centre Journal 35: 37-62.

Knutson, T. n.d. Comparison of Thai and U.S. American cultural values: "Mai Pen Rai Versus Just Do It". April 13, 2013. $<$ http://www.asn.csus.edu/coms/faculty /Pages/Research>

Lakoff, R. T. 1972. Language in context. Language 48. 4: 907-927.

---. 1973. The Logic of politeness, or minding your p's and q's. In Papers from the Ninth Regional Meeting of the Chicago Linguistics Society edited by C. Colum et al, pp. 229-305. Chicago: Linguistic Society.

Leech, G. N. 1980. Language and Tact. Amsterdam: John Bejamins.

---. 1983. Principles of Pragmatics. London: Longman.

Lingli, D. and A Wannaruk. 2010. The effects of explicit and implicit instruction in English refusals. Chinese Journal of Applied Linguistics 33. 3: 93-109.
Mulder, N. 1992. Inside Thai Society: $A n$ Interpretation of Every Life. $3^{\text {rd }}$ edition. Bangkok: Editions Duang Kamol.

Nakata, T., and L. Dhiravegin. 1989. Social and cultural aspects of Thai polity. In S. Prasithrathsint (Ed.), Thailand's National Development: Social and Economic Background. Bangkok: Thai University Research Association.

Nelson, G. L., J. Carson, Batal M. A. and W. E. Bakary. 2002a. Cross-cultural pragmatics: strategy use in Egyptian Arabic and American English refusals. Applied Linguistics 23. 2: 163-189.

---. 2002b. Directness vs Indirectness: Egyptian Arabic and US English communication style. International Journal of Intercultural Relations 26: 39-57.

Quisumbing, L. R. 2004. Peace, tolerance and harmony as core values of Philippine culture. In Teaching AsiaPacific Core Values of Peace and Harmony: A Sourcebook for Teachers/Asia-Pacific Programme of Educational Innovation for Development (APEID), edited by Z . Nan-Zhao and B. Teasdale, pp. 215228. Bangkok, Thailand: UNESCO Asia and Pacific Regional Bureau for Education.

Sadeghi, K. and S. Savojbolaghchilar. 2011. A comparative study of refusal strategies used by Iranians and Americans. International Journal of Academic Research 3. 2: 601-606.

Searle, J. R. 1969. Speech Acts. Cambridge: Cambridge UP. 
MANUSYA: Journal of Humanities Regular 16.1, 2013

Wannaruk, A. 2004. Say "No": a cross cultural comparison of Thais and Americans refusals. English Language Studies Forum 1: 1-22.

---. 2005. Pragmatic transfer in Thai EFL refusal. Paper presented at the $13^{\text {th }}$ Annual KOTESOL International Conference, Sookmyung Women's University, Seoul, Korea.

---. 2008. Pragmatic transfer in Thai EFL refusal. RELC 39. 3: 318-337 


\section{Appendix}

\section{Classification of Refusals}

\section{Direct}
A. Performative (e.g., "I refuse")
B. Nonperformative statement
1. "No" so,")
2. Negative willingness/ability (“I can't!." "I won't", "I don't think

\section{Indirect}
A. Statement of regret (e.g., "I'm sorry ..."; "I feel terrible ...")
B. Wish (e.g., "I wish I could help you ...")
C. Excuse, reason, explanation (e.g., "My children will be home that night." ; "I have a headache.")

\section{Statement of alternative}

1. I can do X instead of Y (e.g., "I'd rather..."; "I'd prefer.")

2. Why don't you do X instead of Y (e.g., "Why don't you ask someone else?")

E. Set condition for future or past acceptance (e.g., "If you had asked me earlier, I would have ...”)

F. Promise of future acceptance (e.g., "I'll do it next time"; "I promise I'll ..." or "Next time I'll ..." -using "will" of promise or "promise")

G. Statement of principle (e.g., "I never do business with friends.")

H. Statement of philosophy (e.g., ... One can't be too careful.”) 


\section{Attempt to dissuade interlocutor}

1. Threat or statement of negative consequences to the requester (e.g., "I won't be any fun tonight" to refuse an invitation)

2. Guilt trip (e.g., waitress to customers who want to sit a while: "I can't make a living off people who only order coffee.")

3. Criticize the request/requester, etc. (statement of negative feeling or opinion); insult/attack (e.g., "Who do you think you are?"; “That's a terrible idea!")

4. Request for help, empathy, and assistance by dropping or holding the request.

5. Let interlocutor off the hook (e.g., "Don't worry about it." "That's okay." "You don't have to,")

6. Self-defense (e.g., "I'm trying my best." "I'm doing all I can do." "I no do nutting wrong.")

\section{J. Acceptance that functions as a refusal}

1. Unspecific or indefinite reply

2. Lack of enthusiasm

\section{K. Avoidance}

1. Nonverbal
a. Silence
b. Hesitation
c. Do nothing
d. Physical departure

2.Verbal
a. Topic switch
b. Joke
c. Repetition of part of request, etc. (e.g., "Monday?")
d.Postponement (e.g., "I'll think about it.")
e. Hedging (e.g., "Gee, I don’t know." "I'm not sure.") 